\title{
Maxillofacial Radiology 168
}

SADJ March 2019, Vol. 74 No. 2 p97

\section{CJ Nortjé}

Below are cases of two very rare genetic disorders. Figures 1, 2 \& 3 are of an inherited form of dwarfism associated with fragile bones, while Figures 4, 5, \& 6 are cases of metabolic disturbances affecting the skull, jaws and teeth. Describe the important radiological features discernible and what are your diagnoses?

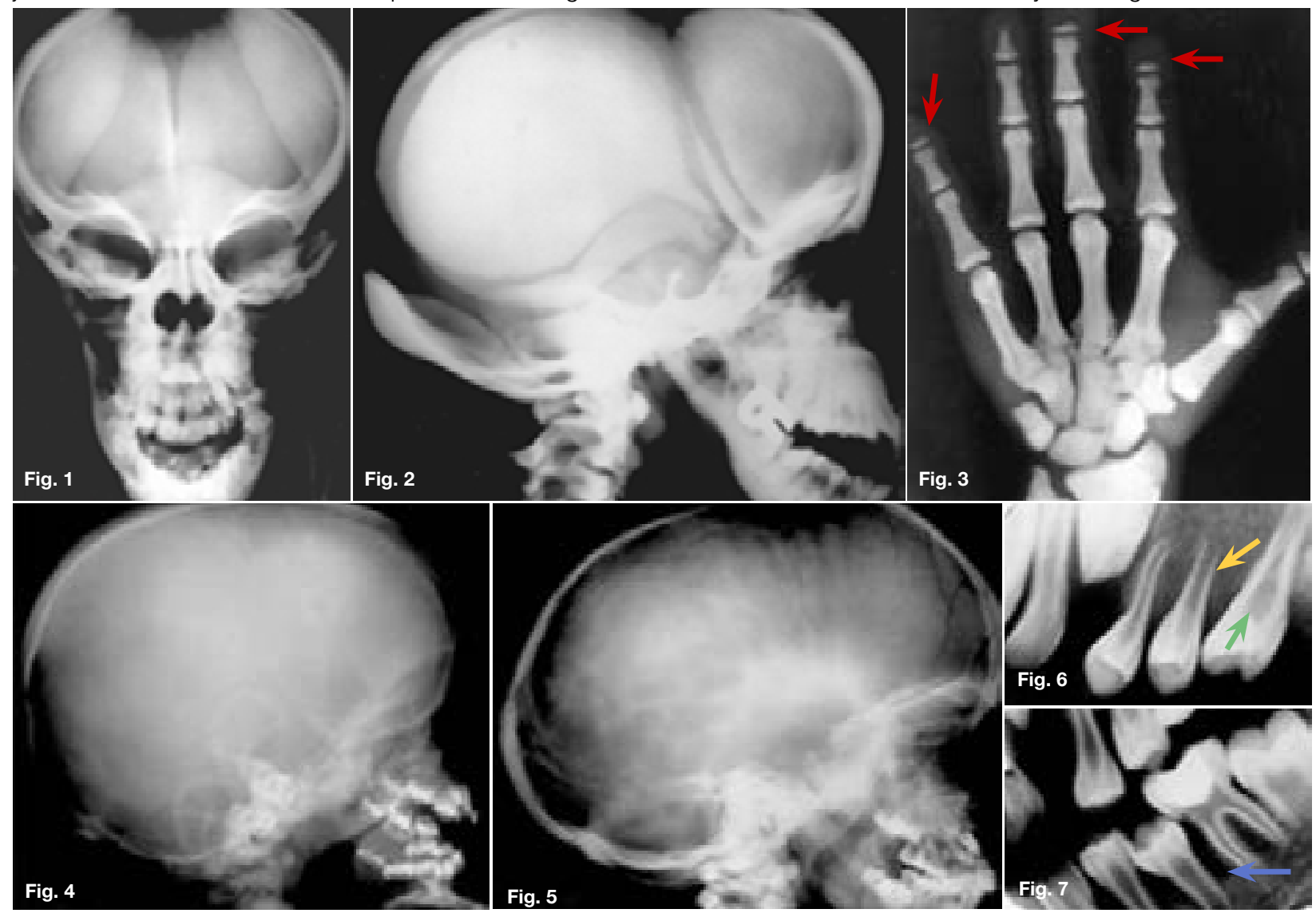

INTERPRETATION

Postero-anterior skull (Fig. 1) and lateral skull radiographs (Fig. 2) showing open anterior fontanelle, dense bones and small maxillary sinuses. In addition, Figure 2 also demonstrates obtuse mandibular angles. The hand-wrist radiograph (Fig. 3) shows incomplete terminal phalanges (red arrows). A diagnosis of Pyknodysostosis was made which is a genetic lysosomal disease characterized by short stature, increased density of the bones, and brittle bones. Other features may include underdevelopment of the tips of the fingers with absent or small nails, an abnormal collarbone (clavicle), distinctive facial features including a large head with a small face and chin, underdeveloped facial bones, a high forehead, and dental abnormalities. These patients are predisposed to osteomyelitis. The diagnosis of Pyknodysostosis is based on physical features and X-ray findings. Figure 4 is a lateral skull radiograph of a patient presenting with bulging of the frontal region of the skull and showing attenuation of the outlines of the dental crypts which is suggestive of a child with vitamin $D$ deficiency. This deficiency results in rickets in childhood and is one of the causes of osteomalacia in adults. Vitamin D acts to increase intestinal calcium uptake, bone calcium mobilization reabsorption. CJ Nortjé: BChD, PhD, ABOMR, DSc. Faculty of Dentistry, University of the Western Cape. E-mail: cnortje@uwc.ac.za

Hypovitaminosis D leads to nondeposition of calcium salt in bone matrix. Figure 5 is a lateral skull radiograph showing generalized radiolucency while figures 6 \& 7 are intra-oral and bitewing radiographs of the same patient showing large pulp cavities (green arrow) and attenuation of the lamina dura and dental crypts (yellow arrow). There is also lack of mineralization of the alveolar crest bone (blue arrow). These radiological features are suggestive of Vitamin D-resistant rickets which is an isolated renal tubular defect inhibiting reabsorption of inorganic phosphates, resulting in hypophosphaturia which is inherited as an X-linked dominant trait. The full manifestation of vitamin D-resistant rickets is rickets or osteomalacia non-respondent to vitamin D therapy, as vitamin D metabolism is normal. However, there is diminished intestinal calcium and phosphate absorption. Patients with the milder form may be slightly shorter than normal siblings, with no other manifestation. Females with vitamin $\mathrm{D}$ resistant rickets tend to show fewer signs and symptoms than do their brothers.

\section{Reference}

Farman AG, Nortje CJ \& Wood R E: Oral and Maxillofacial Imaging, $1^{\text {st }}$ Ed, Mosby. St. Louis, Missouri 1993 pp 145-6, 338-42. 